\title{
OS ROYALTIES DO PRÉ-SAL: UMA ABORDAGEM A PARTIR DO DIREITO E DESENVOLVIMENTO
}

\section{PRE-SALT ROYALTIES: UN APPROACH FROM LAW AND DEVELOPMENT}

\section{Ana Marília Dutra Ferreira da Silva ${ }^{1}$} Patrícia Borba Vilar Guimarães ${ }^{2}$

\section{RESUMO}

No contexto do advento de um Novo Marco Regulatório do Pré-Sal, sobressai as controvérsias acerca da distribuição dos royalties de petróleo e gás natural. Tem-se como escopo geral deste trabalho analisar determinados aspectos controversos da nova regulamentação dos royalties do petróleo. Parte-se da equidade intergeracional a fim de analisar a constitucionalidade da Lei $\mathrm{n}^{\mathrm{o}}$ 12.734/12. Faz-se uma interpretação sistemática dos artigos 20, $\S 1^{\circ} ; 3^{\circ}$, II, III; 170, VII e 225, caput, da Constituição Federal. Conclui-se pela constitucionalidade da Lei $12.734 / 12$, posto coadunar-se com o desenvolvimento nacional, a redução das desigualdades regionais e a promoção da equidade intergeracional.

Palavras-chave: Pré-sal, Distribuição dos royalties, Pacto federativo, Equidadeintergeracional, Lei federal $n^{\circ} 12.734 / 12$

\begin{abstract}
In the context of the New Regulatory Framework for the Pre-Salt, the controversies about the distribution of oil and natural gas royalties are highlighted. This work aims generally at analyzing certain controversial aspects of the new distribution rules of oil royalties. It starts with the intergenerational equity in order to examine the constitutionality of Law 12.734/12. It makes a systematic interpretation of Articles 20, $§ 1 ; 3$, II, III; 170, VII and 225, caput, of the Federal Constitution. The results confirm the constitutionality of Law 12.734/12, since it is consistent with national development, reducing regional inequalities and promoting intergenerational equity.
\end{abstract}

Keywords: Pre-salt, Royalties distribution, Federal pact,Intergenerational equity, Federal law 12.734/12

\footnotetext{
${ }^{1}$ Especialista em direito constitucional (UFRN), mestranda em direito constitucional (UFRN), professora substituta do curso de Direito (UFRN-CERES). E-mail: indexlaw.ojs@hotmail.com

Doutora em Recursos Naturais pela Universidade Federal de Campina Grande (2010). Líder da Base de pesquisa em Direito e Desenvolvimento (UFRN-CNPq).E-mail: indexlaw.ojs@hotmail.com
} 


\section{INTRODUÇÃO}

Os royalties são a forma mais antiga de pagamento de direitos, constituindo uma das modalidades de participação governamental na exploração e produção de petróleo, juntamente com o bônus de assinatura, o pagamento pela ocupação ou retenção da área e a participação especial.

A sua considerável importância para o desenvolvimento do país refere-se ao montante de receitas que deles advém. Entre os anos de 2001 e 2010, foram repassados ao Brasil cerca de 65 bilhões de reais (ANP, 2011) a título de royalties e, no contexto do Présal, tal quantia tende a aumentar consideravelmente.

Nesse contexto, o presente trabalho justifica-se em decorrência do advento de um Novo Marco Regulatório aplicado às jazidas do polígono do Pré-sal, o qual suscitou a necessidade de colocar estas novas leis na pauta de discussão nas searas política, social e econômica, em decorrência das profundas consequências acarretadas por esse novo regime.

Com a descoberta do Pré-sal, a problemática dos royalties tem ocupado espaço na mídia e discussões acadêmicas. A forma de distribuição e aplicação desses recursos é encarada como uma possível solução para os problemas sociais e econômicos pelos quais o país têm passado.

Os recursos petrolíferos são essenciais ao desenvolvimento do país, haja vista o potencial de diminuir as desigualdades de capacidades entre os indivíduos através da promoção de facilidades econômicas e oportunidades sociais. Essa perspectiva desenvolvimentista parte dos estudos de Amartya Sen, para quem o desenvolvimento do país não deve ser medido pelo seu crescimento econômico, mas pelas liberdades individuais.

Como corolário, o planejamento racional e uma política correta de investimentos são essenciais para que os recursos advindos da exploração petrolífera, a exemplo dos royalties, possam construir um legado consistente e que permaneça mesmo após o declínioda respectiva atividade exploratória.

Ressalte-se que a nova realidade vivenciada pelo país, após as descobertas das jazidas petrolíferas do Pré-sal, potencializa a geração de uma considerável quantidade de riquezas e, por conseguinte, a necessidade de apontar-se as maneiras mais eficientes e equânimes de gerenciamento, aplicação e fiscalização deste capital ingressante.

A despeito da relevância jurídica, econômica e política do Pré-sal, alguns aspectos acerca da nova legislação carecem de uma análise mais acurada, a fim de que se entenda o significado das mudanças, suas repercussões e compatibilidade constitucional. 
Atualmente, basicamente, cinco leis regulamentam a distribuição dos royalties, são elas: Lei $\mathrm{n}^{\mathrm{o}} 7.990$, de 28 de dezembro de $1989^{1}$; Lei $\mathrm{n}^{\circ}$ 9.478, de 6 de agosto de $1997^{2}$, conhecida como Lei do Petróleo; Lei $n^{\mathrm{o}} 12.276$, de 30 de junho de $2010^{3}$; Lei $n^{\mathrm{o}} 12.351$, de 22 de dezembro de $2010^{4}$ e, mais recentemente, a Lei $n^{\circ} 12.734$, de 30 de novembro de $2012^{5}$, alvo de muitas controvérsias.

Os maiores embates entre os congressistas referem-se aos royalties a serem recolhidos pela exploração e produção petrolíferas realizadas sob o regime de partilha e as modificações feitas quanto aos contratos de concessão. Discute-se, principalmente, como essas receitas deveriam ser repartidas entre os entes da federação.

Nesta trilha, a Lei 12.734/12 promoveu uma expressiva reformulação dos percentuais distribuídos a determinados entes federados, notadamente aos Estados e Municípios produtores ou confrontantes.

Com a aprovação desta lei, algumas ações foram propostas perante o Supremo Tribunal Federal pugnando pela sua inconstitucionalidade, a exemplo da Ação Direta de Inconstitucionalidade (ADI) 4.916, proposta pelo governador do Estado do Espírito Santo; da ADI 4.917, proposta pelo governador do Estado do Rio de Janeiro; a ADI 4.918, proposta pela Mesa Diretora da Assembleia Legislativa do Rio de Janeiro e a ADI 5.038, proposta pela Associação dos Municípios com Terminais Marítimos, Fluviais e Terrestres de Embarque e Desembarque de Petróleo e Gás Natural.

No dia 18 de março de 2013, a Ministra Relatora Carmén Lúcia deferiu Medida Cautelar na ADI 4.917/DF, movida pelo Governador do Estado do Rio de Janeiro, suspendendo os efeitos dos arts. 42-B; 42-C, da Lei 12.351/10; e dos arts. 48, II; 49, II; 49A; 49-B; 49-C; $\S 2^{\circ}$ do art. 50; 50-A; 50-B; 50-C; 50-D; e 50-E da Lei 9.478/97, com as

\footnotetext{
${ }^{1}$ Institui, para os Estados, Distrito Federal e Municípios, compensação financeira pelo resultado da exploração de petróleo ou gás natural, de recursos hídricos para fins de geração de energia elétrica, de recursos minerais em seus respectivos territórios, plataforma continental, mar territorial ou zona econômica exclusiva, e dá outras providências. (Art. 21, XIX da CF).

${ }^{2}$ Dispõe sobre a política energética nacional, as atividades relativas ao monopólio do petróleo, institui o Conselho Nacional de Política Energética e a Agência Nacional do Petróleo e dá outras providências.

${ }^{3}$ Autoriza a União a ceder onerosamente à Petróleo Brasileiro S.A. - PETROBRAS o exercício das atividades de pesquisa e lavra de petróleo, de gás natural e de outros hidrocarbonetos fluidos de que trata o inciso I do art. 177 da Constituição Federal, e dá outras providências.

${ }^{4}$ Dispõe sobre a exploração e a produção de petróleo, de gás natural e de outros hidrocarbonetos fluidos, sob o regime de partilha de produção, em áreas do pré-sal e em áreas estratégicas; cria o Fundo Social - FS e dispõe sobre sua estrutura e fontes de recursos; altera dispositivos da Lei no 9.478, de 6 de agosto de 1997; e dá outras providências.
} 
${ }^{5}$ Modifica as Leis no 9.478, de 6 de agosto de 1997, e no 12.351, de 22 de dezembro de 2010, para determinar novas regras de distribuição entre os entes da Federação dos royalties e da participação especial devidos em função da exploração de petróleo, gás natural e outros hidrocarbonetos fluidos, e para aprimorar o marco regulatório sobre a exploração desses recursos no regime de partilha.

alterações promovidas pela Lei n. 12.734/2012 até o julgamento final da referida ação (BRASIL, 2014).

O presente trabalho tem como finalidade geral analisar aspectos controversos da nova regulamentação dos royalties do petróleo relativos ao pacto federativo, bem como aos preceitos constitucionais que pugnam pelo desenvolvimento nacional com fulcro na redução das desigualdades regionais e na equidade intergeracional.

Propõe-se a discussão acerca da constitucionalidade da Lei $12.734 / 12$ no que concerne à nova regulamentação dos royalties, notadamente quanto aos critérios de distribuição.

Este debate gira em torno de compreender se o modelo de desenvolvimento proposto pela sistemática constitucional está em consonância com um critério espacial ou com uma divisão mais igualitária das rendas em comento entre os entes subnacionais.

Verifica-se, por conseguinte, a importância que a presente pesquisa dará ao questionamento acerca da maneira e dos pressupostos da distribuição dos royalties, sob o argumento do desenvolvimento nacional e da redução das desigualdades sociais e regionais, um dos objetivos fundamentais da República Federativa do Brasil.

No processo de construção do estudo, o método de abordagem a ser utilizado será o dedutivo. De início, será realizada uma análise sistemática de pesquisas teóricas, além das normas constitucionais e infraconstitucionais relativas ao objeto de estudo, a fim de efetuar a conexão ou aplicação deste arcabouço teórico com a regulação da indústria do petróleo e gás no contexto do Pré-sal.

Nesse diapasão, para o desenvolvimento do estudo, a técnica de pesquisa será mediante pesquisa doutrinária, legislativa e jurisprudencial. Para tanto, serão utilizados livros, artigos científicos e revistas especializadas, bem como leis, decretos, portarias e resoluções vigentes, além da consulta à jurisprudência dos tribunais superiores, notadamente do Supremo Tribunal Federal.

Destaque-se que o estudo priorizará os princípios e diretrizes propostos pela Constituição Federal de 1988, com ênfase em uma hermenêutica constitucional que esteja atenta ao desenvolvimento nacional e à estruturação do Estado Democrático de Direito.

\section{DESENVOLVIMENTO E JUSTIÇA SOCIAL EM AMARTYA SEN}


A questão do desenvolvimento foi tratada com prioridade pelos constituintes, os quais elencaram, no art. $3^{\circ}$, II, da Constituição Federal, o desenvolvimento nacional como objetivo fundamental da República Federativa do Brasil. Questiona-se, por conseguinte, qual o sentido que deve ser conferido a este desenvolvimento.

Atualmente, o pensamento clássico, tanto de viés liberal quanto marxista, segundo o qual o aumento da produção levaria ao bem-estar social, resta ultrapassado(FURTADO, 1997, p. 64). O crescimento econômico é apenas um dos elementos do desenvolvimento, mas a compreensão deste vai além.

De acordo com Ignacy Sachs, o desenvolvimento consiste no processo histórico de apropriação universal da totalidade dos direitos humanos, individuais e coletivos (2009, p. 65). Assim, o desenvolvimento depende de elementos políticos e institucionais. É nesse sentido que Furtado aduz que o crescimento econômico pode ocorrer espontaneamente pelas forças de mercado, mas o desenvolvimento social é fruto de uma ação política (FURTADO, 1997, p. 64).

De fato, a economia por si só não pode ditar as regras, sob pena de produzir desigualdades insustentáveis e arbitrárias que podem ameaçar os valores fundantes das sociedades democráticas (PIKETTY, 2014, p. 9). Deve-se, portanto, recorrer à política e aos instrumentos democráticos ${ }^{6}$ a fim de que o crescimento econômico repercuta positivamente na seara social.

Amartya Sen aduz que o desenvolvimento não pode ser identificado apenas como o crescimento do Produto Nacional Bruto, aumento de rendas pessoais, industrialização, modernização ou avanço tecnológico (SEN, 1999, p. 17). Propõe, assim, o enfoque nas liberdades humanas, de maneira que o desenvolvimento pode ser encarado como a expansão das liberdades reais desfrutadas pelos indivíduos, sendo estas o fim primordial e o principal meio do desenvolvimento (SEN, 1999, p. 52).

As liberdades individuais passam a constituir um meio para avaliação do êxito de uma determinada sociedade, bem como são determinantes da iniciativa individual e da eficácia social, elementos centrais do desenvolvimento (SEN, p. 32-33).

Uma das principais fontes de privação de liberdade é a pobreza, a carência de oportunidades econômicas e a destituição social sistemática, já que elas retiram a liberdade dos indivíduos de nutrir-se adequadamente ou manter a integridade de sua saúde. Enfatizase, entretanto, a análise da privação das capabilities, ou seja, das capacidades dos indivíduos 
${ }^{6}$ Piketty, em sua obra "O capital” atribui notável importância ao papel da política. Segundo o autor, no tocante à redução das desigualdades sociais, não se deve confiar de qualquer argumento proveniente do determinismo econômico. Isso porque, a história da desigualdade é moldada pela forma como os atores políticos, sociais e econômicos enxergam o que é justo e o que não é. Foi assim com a redução das desigualdades entre 1900-1910 e 1950-1960, bem como com a reascensão da desigualdade depois dos anos 1970-1980 (2014, p. 27).

de organizar a sua vida da maneira que valorizam (SEN, 1999, p. 32) e de otimizar suas escolhas reais.

A pobreza não consiste apenas na ausência de recursos financeiros, podendo ser entendida como restrição de capacidades básicas (SEN, 1999, p. 35), de modo que os Estados devem primar pela redução das desigualdades dessas capacidades a fim de promover a justiça social ${ }^{7}$. É necessário, assim, expandir as liberdades substantivas dos indivíduos, de maneira a ampliar as possibilidades de combinações alternativas de funcionamentos.

A redução dessas desigualdades dá-se em aumentar o leque de opções dos indivíduos em escolher aquilo que possui razão para valorizar, a partir da efetivação de direitos, da concessão de oportunidades e entitlements ${ }^{8}$. De acordo com Sen, o aumento das capacidades das pessoas possui relação direta com a promoção das liberdades instrumentais, quais sejam, as liberdades políticas, as facilidades econômicas, as oportunidades sociais, as garantias de transparência e a segurança protetora (SEN, 1999, p. 54-57).

Para os propósitos deste trabalho, destaque-se as facilidades econômicas e as oportunidades sociais. As primeiras consistem nas possibilidades dos indivíduos de utilizar os recursos econômicos para fins de consumo, produção ou troca; ao passo que as segundas consistem nas disposições estabelecidas socialmente nas áreas de educação e saúde (SEN, 1999, p. 55-56), ou seja, decorrem de políticas públicas.

Essas liberdades relacionam-se mutuamente (SEN, 1999, p. 57-58), de maneira que o crescimento econômico é importante ao aumento de renda da população e à arrecadação do Estado que aplicará esses recursos em serviços públicos e seguridade social. Por outro lado, o desenvolvimento humano viabilizado pelo investimento em educação e saúde promove o desenvolvimento econômico.

A concepção de capacidades está no cerne da abordagem de justiça proposta por Amartya Sen, o qual considera que essa perspectiva indica para a relevância das capacidades na avaliação das disparidades sociais (SEN, 2011, p. 267). A justiça de um ato está em sua capacidade de promover liberdades. Isso não quer dizer que o enfoque desta análise resta sobre a efetiva realização de funcionamentos, mas sobre o que os indivíduos são capazes de 
${ }^{7}$ Martha Nussbaum elenca as capacidades básicas que devem ser promovidas pelos governos. Dentre elas estão a vida; a saúde e a integridade físicas; a possibilidade de usar os sentidos, a imaginação, os pensamentos e a razão; a capacidade de sentir afeto; a razão prática; a possibilidade de firmar laços e efetivar relações sociais; a possibilidade do indivíduo relacionar-se com outras espécies; a possibilidade de rir, jogar e aproveitar atividades de recreação; a participação política e o direito à propriedade (NUSSBAUM, 2011, p. 33-34).

${ }^{8} \mathrm{O}$ autor utiliza o termo entitlement ou "intitulamento" para se referir a um conjunto alternativo de bens que podem ser adquiridos através de vários meios de aquisição que são oportunizados a uma pessoa. (SEN, 1999, p. 54).

fazer. Daí a importância da atividade estatal na consecução deste desenvolvimento e na manutenção ou expansão das liberdades e capacidades para as futuras gerações.

O autor não estabelece um padrão ideal de justiça, afastando-se do institucionalismo transcendental, mas reconhece a necessidade de eliminação da injustiça manifesta. A ampliação da justiça social depende, assim, da minimização das situações intoleráveis de injustiça, de modo que a escolha de um modelo justo depende de avaliações comparativas (SEN, 2011, p. 436).

A partir desse arcabouço teórico, percebe-se que a noção de desenvolvimento deve abarcar uma série de fatores, superando questões restritas ao crescimento econômico. Esses fatores implicam na transformação das estruturas sociais, econômicas e institucionais (BERCOVICI, 2005, p. 53-55), relacionando-se com as condições de vida da sociedade, as oportunidades e capacidades de escolhas conferidas aos indivíduos, a sustentabilidade ambiental das atividades econômicas e a efetividade substancial de instrumentos democráticos.

Os royalties do Pré-sal por si só não serão responsáveis pelo desenvolvimento do país, no sentido de aumentar as liberdades substanciais dos indivíduos. É necessário que o recurso financeiro se converta em facilidades econômicas e oportunidades sociais, aumentando as capacidades dos indivíduos ao longo de todo o território brasileiro.

A concentração da distribuição aos Estados e Municípios produtores geram desigualdades manifestas na possibilidade de desenvolvimento do país como um todo. Repercute, também, sobre os direitos de futuras gerações, às quais devem ser oferecidas as mesmas condições de desenvolvimento, inclusive com os reflexos positivos das conquistas das gerações atuais (COSTA e SANTOS, 2013, p. 22).

\section{EVOLUÇÃO DO MARCO REGULATÓRIO DA DISTRIBUIÇÃO DOS ROYALTIES DE PETRÓLEO}

As cinco principais leis que regulamentam atualmente a distribuição dos royalties, são: i) a Lei 7.990/89; ii) a Lei 9.478/97, conhecida como Lei do Petróleo; iii) a Lei 12.276/10; iv) a Lei 12.351/10 e v) a mais recente e discutida na ADI 4.917, Lei 12.734/12. 
Destas cinco leis, três foram promulgadas no contexto do Pré-sal, inserindo as mudanças controversas na distribuição dos royalties.

A Lei 7.990/89 direciona a distribuição dos royalties aos Estados, Distrito Federal e Municípios, no percentual de 5\% (cinco por cento) sobre o valor extraído, obedecidos os seguintes critérios: i) 70\% (setenta por cento) aos Estados produtores, ii) 20\% (vinte por cento) aos Municípios produtores e 10\% aos Municípios onde se localizam instalações marítimas ou terrestres para as atividades de embarque e desembarque de óleo bruto e/ou gás natural.

No caso de produção na plataforma continental, parcela de 5\% (cinco por cento) da referida compensação financeira aos Estados, Distrito Federal e Municípios seria distribuída consoante os seguintes percentuais: $30 \%$ (trinta por cento) aos Estados confrontantes; $30 \%$ (trinta por cento) aos Municípios confrontantes e suas respectivas áreas econômicas; 10\% (dez por cento) aos Municípios com instalações de embarque e desembarque de petróleo e gás natural e 10\% (dez por cento) ao Fundo Especial.

$\mathrm{O}$ art. $9^{\circ}$, da supracitada lei, determina a transferência pelos Estados aos Municípios de $25 \%$ (vinte e cinco por cento) da parcela que lhe couber dos royalties, respeitando os critérios estabelecidos pelo art. 158, inciso IV e parágrafo único, da Carta Magna.

A partir da Emenda Constitucional $n^{\circ} 9$ houve a flexibilização do monopólio da União sobre as atividades de exploração e produção de petróleo e, por conseguinte editou-se uma nova lei regulamentadora, qual seja, a Lei 9.478/97.

A Lei 9.478/97 ou Lei do Petróleo, juntamente com o Decreto Federal 2.705/98, consistem em instrumentos jurídicos de destaque na disciplina jurídica dos royalties.

Os arts. 47 ao 49, daquela Lei apontam os procedimentos e regras gerais a serem seguidos no regime de concessão então estabelecido, regulando a distribuição das parcelas acima de $5 \%$ até $10 \%{ }^{9}$; ao passo que este Decreto definiu os conceitos jurídicos e critérios indispensáveis aos cálculos e cobranças de todas as participações especiais indicadas na Lei do Petróleo, incluindo, portanto, os royalties (MANOEL, 2003, p. 28).

Consoante o art. 49, da Lei 9.748/97, a parcela do valor do royalty que exceder a cinco por cento da produção será distribuída da seguinte forma: 52,5\% (cinquenta e dois e meio por cento) aos Estados onde ocorrer a produção; 15\% (quinze por cento) aos Municípios produtores; 7,5\% (sete e meio por cento) aos Municípios que sejam afetados pelas operações de embarque e desembarque de petróleo e gás natural.

Quando a lavra ocorrer na plataforma continental, os percentuais serão, de acordo com a lei supra: 22,5\% (vinte e dois e meio por cento) aos Estados confrontantes; 22,5\% 
(vinte e dois e meio por cento) aos Municípios confrontantes; 7,5\% (sete e meio por cento) aos Municípios afetados por operações de embarque e desembarque de petróleo e gás e $7,5 \%$ (sete e meio por cento) ao Fundo Especial.

${ }^{9}$ Destaque-se que, no que tange aos royalties no percentual de 5\%, a distribuição deve ser feita nos termos da Lei 7.990/89.

Em 2001, a ANP editou a portaria 29/2001 (BRASIL, 2001), a qual estabelece critérios a serem adotados a partir do primeiro dia de janeiro de 2002, com o fim de distribuição do percentual de 7,5\% (sete e meio por cento) sobre a parcela dos royalties que exceder 5\% (cinco por cento) da produção de petróleo ou gás natural de cada campo, a ser efetuada aos Municípios afetados pelas operações de embarque e desembarque de petróleo e gás natural.

Nesta trilha, a distribuição do percentual deu-se da seguinte forma: i) $40 \%$ (quarenta por cento) da parcela será destinado ao Município onde se localiza a instalação de embarque e desembarque de petróleo ou gás natural; ii) $60 \%$ (sessenta por cento) aos Municípios pertencentes à zona de influência da instalação.

A descoberta de enormes reservatórios de petróleo offshore, localizados entre o Espírito Santo e Santa Catarina, cuja expectativa de produção inicialmente era de 50 bilhões de barris (SIQUEIRA, 2011, p. 148), acarretou a adoção de um modelo complementar aos contratos de concessão.

Ocorre que, sendo o petróleo um bem estratégico e tendo em conta o alto potencial de rentabilidade e baixo risco do empreendimento, pretendeu-se reavaliar e modificar a legislação petrolífera concernente ao polígono do Pré-Sal e outras áreas estratégias. O potencial de produção das jazidas do Pré-sal desdobra-se, pois, nas tentativas de modificação dos critérios existentes de distribuição dos royalties.

Assim, em razão desse novo contexto, os royalties passaram a incidir nos regimes de cessão onerosa de direitos de exploração e produção à Petrobras e no de partilha da produção, nos termos das Leis 12.276/10 e 12.351/10, respectivamente.

A distribuição dessas receitas no âmbito da cessão onerosa assemelha-se à realizada pelo regime de cessão comum, de maneira que o art. $5^{\circ}$, da respectiva lei, determina que a parcela do valor dos royalties que representar 5\% (cinco por cento) da produção será distribuída nos termos da Lei 7.990/89; enquanto que o valor que exceder aquela porcentagem respeitará a Lei 9.478/97.

Por outro lado, a Lei 12.351/10 modifica o art. 49, da Lei do Petróleo, a fim de direcionar integralmente as parcelas dos royalties que cabem à administração direta da 
União, pela exploração das áreas do Pré-Sal licitadas sob o regime de concessão, ao Fundo Social do Pré-Sal - FS.

Consoante aduz Alves e Xavier, não se trata de uma distribuição diferenciada dos royalties do Pré-sal, mas da inserção de uma nova regra de distribuição para os royalties decorrentes de jazidas do Pré-sal que serão exploradas sob o regime de concessão (ALVES e XAVIER, 2013, p. 90-91).

As maiores controvérsias e embates entre os congressistas referem-se aos royalties a serem recolhidos pela exploração e produção petrolíferas realizadas sob o regime de partilha. Isso porque, a Lei 12.351/10 aumenta as alíquotas dos royalties, cuja distribuição permanece concentrada nos Estados e Municípios produtores ou confrontantes.

Insatisfeitos com o Novo Marco Jurídico do Pré-Sal, os Estados e Municípios não produtores esforçaram-se na aprovação da Lei 12.734/12, a qual modifica as regras de distribuição dos royalties entre os entes da Federação.

$\mathrm{O}$ art. 42-B, acrescentado pelo art. $2^{\circ}$, da Lei $12.734 / 12$, fixa a distribuição dos royalties devidos em função da produção de petróleo, gás natural e hidrocarbonetos sob oregime de partilha.

Ocorrendo a produção em terra, rios, lagos, ilhas lacustres ou fluviais, a divisão será da seguinte forma: 20\% (vinte por cento) para os Estados ou o Distrito Federal produtores; $10 \%$ (dez por cento) para os Municípios produtores; 5\% (cinco por cento) para os Municípios afetados pelas operações de embarque e desembarque de petróleo, gás natural e hidrocarbonetos, consoante os critérios da ANP; $25 \%$ (vinte e cinco por cento) para a constituição de fundo especial, a ser distribuído entre Estados e o Distrito Federal; 25\% (vinte e cinco por cento) para a constituição de fundo especial a ser distribuído entre os Municípios; $15 \%$ (quinze por cento) para a União, a ser destinado ao Fundo Social, deduzidas as parcelas destinadas aos órgãos da administração pública direta.

No caso de a produção ocorrer na plataforma continental, mar territorial ou zona econômica exclusiva, o percentual passa a ser de: 22\% para os Estados confrontantes; $5 \%$ (cinco por cento) para os Municípios confrontantes; 2\% (dois por cento) para os Municípios afetados por operações de embarque e desembarque de petróleo, gás natural e demais hidrocarbonetos fluidos; $24,5 \%$ (vinte e quatro e meio por cento) para a constituição de fundo especial, a ser distribuído entre Estados e Distrito Federal; 24,5\% (vinte e quatro e meio por cento) para constituição de fundo especial a ser distribuído entre os Municípios e $22 \%$ (vinte e dois por cento) para a União, a ser destinado ao Fundo Social, deduzidas as parcelas destinadas aos órgãos específicos da administração direta da União. 
Houve, portanto, o estabelecimento de um percentual significativamente menor do que aqueles estabelecidos para os contratos de concessão pela até então redação vigente das Leis 7.990/89 e 9.478/97. Além disso, houve um recrudescimento nas rendas direcionadas para repartição entre os demais Estados e Municípios.

Ademais, destaque-se dois pontos importantes neste dispositivo: i) a preocupação em não beneficiar duplamente um ente federativo, de maneira a melhor racionalizar a destinação dessas rendas; ii) o estabelecimento de um teto da soma dos valores que um Município possa receber, considerando os royalties devidos em razão do próprio artigo, acrescidos daqueles devidos em decorrência dos arts. 48 e 49, da Lei 9.478/97 e da participação devida consoante o art. 50, §2 , III, também da Lei do Petróleo.

$\mathrm{O}$ art. $3^{\circ}$, da Lei 12.734/12, modifica o art. 48, II, da Lei 9.478/97, no sentido de diminuir os percentuais das parcelas dos royalties conferidos aos entes federados confrontantes previstos nos contratos de concessão, que representar 5\% (cinco por cento) da produção, no caso de a lavra ocorrer na plataforma continental. Da mesma forma, aumentase os percentuais concedidos aos fundos especiais a ser distribuídos aos Estados, Distrito Federal e Municípios não confrontantes e ao Fundo Social.

Seguiu-se a mesma lógica estabelecida no art. 42-B, da Lei 12.351/10, exposta acima. No mesmo sentido, a modificação do art. 49, II, da Lei do Petróleo, a qual reduz os percentuais da parcela dos royalties que exceder $5 \%$ (cinco por cento) da produção, quando a lavra ocorrer na plataforma continental.

Os arts. 49-A, 49-B, 49-C, da Lei 9.478/97 foram acrescidos com o fito de diminuir progressivamente os percentuais concedidos aos Municípios confrontantes e áreas geoeconômicas, referente aos contratos de concessão, até o percentual de $4 \%$ (quatro por cento) e aumentar o montante destinado aos fundos especiais que distribuirão recursos aos Estados, Distrito Federal e Municípios.

A presidência, por sua vez, vetou o texto legal que determinava esse decréscimo de receita quanto aos contratos em vigor; não obstante, o Congresso Nacional, no dia 07 de março de 2013, derrubou o veto, de maneira a restabelecer o texto original da lei.

Como visto anteriormente, houve o deferimento da Medida Cautelar na ADI 4.917/DF, suspendendo os efeitos dos arts. 42-B; 42-C, da Lei 12.351/10; e dos arts. 48, II; 49, II; 49-A; 49-B; 49-C; $\S 2^{\circ}$ do art. 50; 50-A; 50-B; 50-C; 50-D; e 50-E, da Lei Federal n. 9.478/97, com as alterações promovidas pela Lei n. 12.734/2012.

Antes de passar ao capítulo seguinte, importante notar alguns dados expostos no Anuário Estatístico Brasileiro de Petróleo, Gás Natural e Biocombustíveis do ano de 2014.

Segundo este documento, entre os anos 2004 e 2013, a produção em terra decresceu; ao passo que a produção na plataforma continental aumentou. No âmbito desta 
produção offshore houve um aumento de cerca de $14 \%$ (quatorze por cento) na produção pós-sal; ao passo que a produção do pré-sal aumentou cerca de 97\% (noventa e sete por cento) (ANP, 2014).

Por sua vez, no ano de 2013, a produção do Estado do Rio de Janeiro representou quase $79 \%$ de toda a produção marítima de petróleo do país (ANP, 2014). Essa porcentagem reflete na quantidade de royalties percebida por esta unidade da federação, de maneira que naquele mesmo ano cerca de $61 \%$ (sessenta e um por cento) dos royalties distribuídos às unidades da federação foram destinados ao Estado do Rio de Janeiro.

Percebe-se, portanto, que a tendência da legislação em vigor de distribuição das participações governamentais em comento é beneficiar desproporcionalmente determinadas unidades da federação. A Lei 12.734/12, por sua vez, pretende mitigar a lógica de um certo "determinismo físico" sobre as regras de rateio dos royalties, a qual desdobra-se em uma hiperconcentração espacial desses recursos em poucas regiões (SERRA, 2007, p. 80).

\section{A EQUIDADE INTERGERACIONAL COMO VETOR DA JUSTIÇA SOCIAL E DO DESENVOLVIMENTO NACIONAL}

Como visto anteriormente, o desenvolvimento não se confunde com o crescimento econômico, sendo o desenvolvimento uma mudança qualitativa e não apenas quantitativa, de maneira que engloba a noção de crescimento (BERCOVICI, 2005, p. 108). Consiste em um processo de longo prazo, induzido por políticas públicas ou programas governamentais (COMPARATO, 1999, p. 89-90).

Essas políticas e programas dão-se em duas dimensões particularmente importantes para este trabalho: a econômica e a social. A primeira consiste em um crescimento endógeno, porque fundado nos fatores internos de produção, sustentado da produção de bens e serviços (COMPARATO, 1999, p. 89-90); ao passo que a dimensão social consiste na aquisição da progressiva igualdade das condições básicas de vida (COMPARATO, 1999, p. 89-90).

O art. 170, da Constituição Federal, onde restam os princípios gerais da ordem econômica propõe-se a conciliar esses dois elementos, visando o desenvolvimento econômico com base na existência digna, justiça social, defesa do meio ambiente e redução das desigualdades regionais e sociais.

O Estado desenvolvido caracteriza-se pela a harmonização entre o padrão de modernização e a tutela dos valores coletivos (ELALI, 2007, p. 69), a exemplo da cidadania e da dignidade humana. A ênfase estrita na modernização e no crescimento não confere 
desenvolvimento a um Estado, visto que este depende da tutela do consumidor, de educação, do meio ambiente, do trabalho e etc. (ELALI, 2007, p. 69).

A conciliação desses fatores nos leva ao conceito de desenvolvimento sustentável, presente no art. 225, caput, da Constituição Federal e no art. $4^{\circ}$, I, da Lei 6.938, de 31 de agosto de $1981^{10}$, segundo a qual um dos objetivos da Política Nacional do Meio Ambiente é a compatibilização do desenvolvimento econômico-social com a preservação da qualidade do meio ambiente e do equilíbrio ecológico.

O desenvolvimento sustentável consiste em explorar equilibradamente os recursos naturais, satisfazendo as necessidades e bem-estar das presentes gerações e preservando o interesse das futuras (SIL, 2002, p. 26-27). Dessa forma, necessita de uma equânime redistribuição dos resultados do processo produtivo e a erradicação da pobreza, de maneira a reduzir as desigualdades dos padrões de vida da população (SILVA, 2002, p. 27). Pugna-se por um comportamento responsável em relação às gerações futuras.

Percebe-se, assim, que o desenvolvimento sustentável possui como um de seus pilares a equidade ou justiça intergeracional. A previsão de concessão de um direito para gerações futuras é inexistente até a Constituição de 1988, de maneira que a partir desta os interesses de quem viverá no futuro passa a ser considerado.

A equidade intergeracional prevista no art. 225, da Constituição Federal, desdobrase também em um princípio, qual seja, o princípio da solidariedade intergeracional, segundo o qual as futuras gerações também devem usufruir, de forma sustentável, dos recursos naturais (MILARÉ, 2009, p. 812).

Sendo um princípio, constitui um dos alicerces do sistema jurídico brasileiro, definindo a lógica e a racionalidade do sistema normativo, conferindo-lhe um sentido harmônico (MELLO, 2009, p. 53). Por conseguinte, consoante aduz Mello, a violação de um princípio traduz-se em insurgência contra todo um sistema e a subversão de seus valores fundamentais (2009, p. 53).

Uma série de compromissos internacionais assumidos pelo país refere-se a obrigações assumidas perante as gerações futuras, a exemplo da Convenção sobre Diversidade Biológica, promulgado pelo decreto 2.519/98 e a Convenção-Quadro das Nações Unidas sobre Mudança no Clima, promulgada através do decreto 2.652/98.

A equidade intergeracional pode ser definida como a manutenção do mesmo potencial de desenvolvimento econômico e cultural entre as gerações, havendo uma igualdade no direito de usufruir os recursos naturais e no dever de preservá-los. 
${ }^{10}$ Dispõe sobre a Política Nacional do Meio Ambiente, seus fins e mecanismos de formulação e aplicação, e dá outras providências.

Uma das principais teóricas do tema foi Edith Brown Weiss, segundo a qual a noção da equidade intergeracional desdobra-se em três princípios: i) a conservação das opções; ii) a conservação da qualidade ambiental e iii) a conservação do acesso aos recursos naturais (BORDIN, 2008, p. 41).

Da equidade intergeracional resulta o dever de assegurar a diversidade dos recursos ou, sendo impossível fazê-lo, deve-se promover desenvolvimentos tecnológicos que permitam a substituição dos recursos esgotados (BORDIN, 2008, p. 41). Requer-se, doutra feita, um equilíbrio entre degradação ambiental causada no presente e o capital e desenvolvimentos tecnológicos a serem legados para o futuro.

A dimensão coletiva da dignidade da pessoa humana em uma sociedade de risco ${ }^{11}$, como a contemporânea, confere relevância aos interesses das gerações futuras e a sua proteção (CARVALHO, 2008, p. 33).

Desse modo, os direitos personalíssimos das gerações atuais, como os direitos à vida, à saúde e ao usufruto da propriedade, em suas condições pessoais e ambientais, devem ser exercidos de forma compatível às gerações futuras (CARVALHO, 2008, p. 33).

Observe-se que toda atividade estatal de planejamento e de alcance temporal dilatado traz consequências a terceiros que não puderam intervir (DERANI, 2008, p. 259). O dever de promover a equidade intergeracional à coletividade é, portanto, primordialmente do Estado, tanto a nível internacional como nacional. Tem-se, nesse contexto, o objetivo prático de manutenção do modo de vida presente, da organização social (DERANI, 2008, p. 258).

Os recursos naturais exauríveis, como o petróleo, gás natural e derivados são finitos. A regulamentação de sua exploração e produção, bem como a maneira de distribuição dos recursos advindos destas atividades repercutem no modo de vida das gerações futuras.

Uma importante teoria econômica que justifica a cobrança dos royalties é a desenvolvida por Hotelling com base na ideia de um custo de oportunidade intertemporal (BREGMAN, 2007, p. 24). Desta feita, além dos custos de extração, o proprietário de uma mina deveria receber uma renda que o compensasse da impossibilidade de extração futura do minério. 
${ }^{11}$ Nas palavras de Cristiane Derani, “os riscos originados de novas práticas desenvolvidas, como a tecnologia atômica, a engenharia genética etc., lançam uma perspectiva de efeitos negativos nunca antes previstos, capazes de alterar os elementos básicos de sobrevivência humana, como alimento, ar e temperatura. (...) A conclusão de que o desenvolvimento da atividade industrial pode acarretar consequências graves à saúde e bem-estar dos indivíduos, além de levar à inviabilidade de sua existência por minar suas bases de produção, conduziu a esta nova perspectiva orientada para o futuro". (2008, p. 258-259).

Apesar das críticas à teoria de Hotelling ${ }^{12}$, necessário ressaltar a sua importância nos debates acerca das questões sobre equidade entre as gerações. Esta visão e os seus desdobramentos engloba a questão da temporalidade, a qual sustenta o dilema ético, no que tange às decisões a serem tomadas quanto à extração de recursos não renováveis (FONTES, 2010, p. 79). Justifica-se o pagamento dos royalties como um ressarcimento dos recursos exauríveis para as gerações posteriores.

Esse viés compensatório pode ser alcançado pelo financiamento do desenvolvimento científico e tecnológico no setor energético, seja no aprimoramento da eficiência no uso dos hidrocarbonetos; seja no desenvolvimento de fontes de energia alternativa (SERRA, 2005, p. 76).

Necessário o financiamento na construção da infraestrutura necessária à diversificação produtiva ou a montagem de um fundo previdenciário que minimize os efeitos depressivos ocasionados pelo esgotamento das jazidas minerais (SERRA, 2005, p. 76).

Além disso, deve haver investimento no capital humano ${ }^{13}$, de maneira a atentar para direitos fundamentais sociais, como a saúde, a moradia e a educação (TORRONTEGUY, 2009, p. 84). Isso contribui para a diminuição da pobreza sistêmica, a qual inclui as impossibilidades de usufruto de bens intelectuais (COSTA e SANTOS, 2013, p. 23).

A questão da distribuição dos royalties também se imbrica com a redução das desigualdades regionais e com o desenvolvimento nacional. Ambos os objetivos, crivados na Constituição, consistem em diretrizes, dotada de caráter constitucionalmente conformador (GRAU, 2006, p. 215-219).

Eles possuem teor obrigatório e vinculam todos os poderes públicos, os quais devem atuar em sua concretização (BERCOVICI, 2005, p. 105). Doutra feita, qualquer política que se contrapõe aos objetivos constitucionais, desconsiderando ou prejudicando o desenvolvimento e a diminuição dos desequilíbrios regionais é inconstitucional (BERCOVICI, 2005, p. 112-113) e ilegítima.

Constituindo também um princípio da ordem econômica, pois consta do art. 170, VII, da Constituição Federal, infere-se que as atividades econômicas desenvolvidas no país 
${ }^{12}$ Várias críticas são feitas ao modelo de Hotelling, dentre elas, o fato de que ele não leva em consideração alguns aspectos concernentes à indústria do petróleo, como a imperfeição concorrencial, os custos variáveis, os avanços da tecnologia, as questões geopolíticas, as decisões sobre exploração e a descoberta de novas reservas (FONTES, 2010, p. 80).

${ }^{13}$ Segundo Jeffrey D. Sachs, a utilização dos recursos petrolíferos tem geralmente quatro destinos possíveis: preservação das reservas inexploradas ou transformação das rendas em ativos financeiros, ativos físicos ou capital humano (Apud BERCOVICI, 2011, p. 345).

devem observar o princípio da redução das desigualdades regionais e sociais (CABRAL e FRANÇA, 2008, p. 213), inclusive a legislação petrolífera.

Observe-se que a redução das desigualdades regionais e sociais é um dado de equidade. Isso porque, um maior equilíbrio entre as regiões e classes sociais aumenta a circulação de recursos financeiros, o consumo e a produção, por exemplo (ELALI, 2007, p.73).

O objetivo da redução das desigualdades regionais relaciona-se com o federalismo cooperativo, bem como com o desenvolvimento nacional, já que este é um interesse de todos os entes federados (PASSEGGUI, 2010, p. 155).

Ademais, a harmonização nacional e a implementação da concepção de solidariedade social são de interesse do Estado (ELALI, 2007, p. 72), já que a busca pela redução das disparidades regionais tem a ver com o desenvolvimento pleno do país.

Uma das principais formas que a indústria de petróleo e gás natural possui de contribuir com este desiderato é através das rendas dos royalties, as quais alcançam patamares significativos (BERCOVICI, 2011, p. 344), que devem ser devidamente geridos à luz dos preceitos expostos.

Nessa trilha, Bercovici aduz que, no caso de a interpretação do art. $20, \S 1^{\circ}$, da Constituição Federal, for no sentido de os Estados, Municípios, Distrito Federal terem direito a receber recursos a título de compensação financeira pela exploração de petróleo e gás em domínio da União - e este é o nosso entendimento -, a única alternativa constitucionalmente adequada, tendo em vista os arts. $3^{\circ}$, III, e 170, VII, da Carta Magna, é a repartição destes recursos entre todos os entes da Federação (2011, P.344).

A preponderância do critério de proximidade física é mitigada em prol de uma maior concretização dos ditames constitucionais. Seja a nível nacional ou subnacional, as receitas dos royalties devem respeitar o princípio da equidade intergeracional, os fundamentos do desenvolvimento nacional e da redução das desigualdades regionais e sociais. 
Faz-se isso, a partir de uma repartição mais equânime dessas receitas, consoante propõe a Lei 12.734/12. Além disso, no âmbito das esferas federadas é necessário que haja a elaboração de políticas públicas as quais estejam em consonância com as problemáticas locais e regionais, assim como a elaboração de projetos de desenvolvimento de capitais humano, tecnológico e físicos.

\section{CONCLUSÃO}

O desenvolvimento nacional e a redução das desigualdades regionais são objetivos fundamentais da República brasileira. $\mathrm{O}$ seu entendimento não deve equivaler à concepção de crescimento econômico, mas perpassa por fatores sociais e institucionais, devendo ser analisado a partir do aumento das liberdades dos indivíduos, de suas capabilities.

As atividades econômicas, a exemplo daquelas promovidas pela indústria petrolífera, possuem importância no processo de desenvolvimento, já que através delas pode-se gerar riquezas, as quais devem ser utilizadas na promoção de facilidades econômicas e oportunidades sociais. O desenvolvimento do país depende, assim, da atuação do Estado visando as presentes e futuras gerações.

Os royalties do petróleo apenas poderão constituir instrumentos de desenvolvimento intergeracional do país se houver uma regulamentação que possa garantir uma distribuição mais equânime entre os entes da federação, eliminando injustiças manifestas a partir do cumprimento do texto constitucional.

O reflexo disso para o direito do petróleo e gás natural consiste em coadunar a regulamentação legal com as diretrizes constitucionais. Uma interpretação sistemática com os arts. $3^{\circ}$, II e III, e 170, VII, da Carta Magna, demonstra a intenção do legislador constituinte distribuir as rendas advindas da exploração de um recurso de propriedade da União para os entes subnacionais com o fito de promover o desenvolvimento nacional e diminuir as desigualdades regionais.

As Leis 7.990/89 e 9.478/97, no entanto, promoveram uma situação de patente desequilíbrio na distribuição desses royalties, deixando de observar o pacto federativo de cooperação e a necessidade de desenvolvimento a nível regional. Assim, Estados como o Rio de Janeiro e Espírito Santo, pelo simples fato de serem confrontantes com as jazidas do Pré-sal teriam o potencial de perceber valores significativos, em detrimento dos demais entes da federação.

A partir de uma melhor distribuição dos recursos para que cada ente subnacional invista nos capitais humano, tecnológico e físico, mitiga-se o critério espacial, a fim de 
realçar o caráter temporal de promoção do desenvolvimento também pautado nas futuras gerações, com fulcro no art. 225, da Constituição Federal.

Algumas ações tramitam perante o Supremo Tribunal Federal pugnando pela declaração de inconstitucionalidade da Lei 12.734/12. A ministra Carmén Lúcia deferiu o pedido cautelar feito pelo governador do Rio de Janeiro na ADI 4.917, de maneira a suspender os principais dispositivos da lei guerreada.

Basicamente, os artigos suspensos diminuíram os percentuais da parcela dos royalties a serem destinados aos Estados, Distrito Federal e Municípios produtores ouconfrontantes; ao passo que aumentou os recursos a serem distribuídos aos entes federados não produtores ou não confrontantes.

Além disso, estabeleceram regras que conferiram uma maior racionalidade à maneira de repartição dessas receitas, estabelecendo um teto ao repasse das verbas aos Municípios produtores ou confrontantes e àqueles afetados pelas operações de embarque e desembarque.

Uma possível declaração de inconstitucionalidade da Lei 12.734/12 violará importantes preceitos e diretrizes constantes da Constituição Federal brasileira. Neste trabalho, destacaram-se a equidade intergeracional; a redução das desigualdades regionais e o desenvolvimento nacional.

Não há que se conceber o fato de poucos entes subnacionais serem desproporcionalmente beneficiados pela exploração de um recurso exaurível de propriedade da União, cujo declínio da produção prejudicará o desenvolvimento de todo o país e das gerações futuras. A manutenção da legislação anterior à Lei 12.734/12 viola, assim, importantes fundamentos da República Federativa brasileira.

Os recursos advindos dos royalties serão importantes instrumentos de efetivação das de políticas públicas no âmbito das esferas subnacionais, as quais poderão investir em projetos e programas de desenvolvimento de capitais humano, tecnológico e físicos, direcionados à manutenção da equidade intergeracional.

Cabe ao Supremo Tribunal Federal realizar uma interpretação sistemática e conforme à Constituição, de maneira obstar a perpetuação de uma situação de hiperconcentração espacial das rendas do petróleo, a partir do entendimento da relevância dos royalties para o desenvolvimento do país.

O presente trabalho contribui em verificar que a questão se resume a uma correta exegese do sentido da ordem econômica e da ordem social, bem como dos direitos 
fundamentais delimitados pela Constituição Federal, a partir de uma perspectiva neodesenvolvimentista seniana. O objetivo imposto ao Estado deve ser entendido como de promoção do desenvolvimento intergeracional com fulcro nos valores de justiça social.

\section{REFERÊNCIAS}

ALVES, Victor Rafael Fernandes; XAVIER, Yanko Marcius de Alencar. Evolução regulamentar da distribuição dos royalties do petróleo. In: XAVIER, Yanko Marcius de

Alencar et al (Org.). Direito do petróleo, gás natural e biocombustíveis: estudo em homenagem à professora Helenice Vital. Natal: EDUFRN, 2013, p. 81-98.

ANP. Anuário estatístico brasileiro do petróleo, gás natural e biocombustíveis 2011. Rio de Janeiro: ANP, 2011.

Anuário Estatístico de Petróleo, Gás Natural e Biocombustíveis 2014. Disponível:

$<$ http://www.anp.gov.br/?pg=71976\&m=anu\%E1rio\&t1=\&t2=anu\%E1rio\&t $3=\& \mathrm{t} 4=\& \mathrm{ar}=0$ $\underline{\text { \&ps }=1 \& \text { cachebust }=1421887435469}>$. Acesso em: 21 de ago. 2014.

BERCOVICI, Gilberto. Constituição Econômica e Desenvolvimento: uma leitura a partir da Constituição de 1988. São Paulo: Malheiros, 2005.

2011.

Direito econômico do petróleo e dos recursos minerais. São Paulo: Quartier Latin,

BORDIN, Fernando Lusa. Justiça entre as gerações e a proteção do meio ambiente. In: Revista de Direito Ambiental. São Paulo: Revista dos Tribunais, 2008, ano 13, n. 52, p. 37 61, out./dez. 2008.

BRASIL. Portaria ANP $n^{o}$ 29, de 22.2.2001. Estabelece os critérios a serem adotados a partir de $1^{\circ}$ de janeiro de 2002, para fins de distribuição do percentual de 7,5\% (sete e meio por cento) sobre a parcela do valor dos royalties que exceder a $5 \%$ (cinco por cento) da produção de petróleo ou gás natural de cada campo, a ser efetuada aos Municípios que sejam afetados pelas operações de embarque e desembarque de petróleo ou gás natural. Disponível em:

<http://nxt.anp.gov.br/NXT/gateway.dll/leg/folder_portarias_anp/portarias_anp_tec/2001/fe vereiro/panp\%2029\%20-\%202001.xml>. Acesso em 1 de fev. 2015.

BREGMAN, Daniel. Formação, Distribuição e Aplicação de Royalties de RecursosNaturais: O Caso do Petróleo do Brasil. Dissertação de Mestrado em Economia. Instituto deEconomia. UFRJ. 2007, 150 p. Disponível em:〈http://www.gee.ie.ufrj.br>. Acesso em: 12 jan. 2015. 
CABRAL, Indhira de Almeida; FRANÇA, Vladimir da Rocha. A utilização das normas tributárias indutoras para a concretização do princípio constitucional da redução das desigualdades sociais e regionais. In: XAVIER, Yanko Marcius de Alencar et al. (Org.). Regulação econômica e proteção dos direitos humanos: um enfoque sob a ótica do direitoeconômico. Fortaleza: Fundação Konrad Adenauer, 2008, p. 207-232.

CARVALHO, Délton Winter de. Sociedade do risco global e o meio ambiente. Revista deDireito Ambiental. São Paulo: Revista dos Tribunais, 2008, ano 13, n. 52, p. 27-36, out./dez.2008.

COMPARATO, Fábio Konder. A afirmação histórica dos direitos humanos. São Paulo: Saraiva, 1999.

COSTA, Hirdan Katarina de Medeiros; SANTOS, Edmilson Moutinho dos. Rendas de hidrocarbonetos e o princípio da justiça intra e intergeracional: direitos fundamentais e sustentabilidade. In: XAVIER, Yanko Marcius de Alencar et al. (org.). Direito do petróleo, gás natural e biocombustíveis: estudos em homenagem à professora Helenice Vital. Natal: EDUFRN, 2013, p. 11-40.

DERANI, Cristiane. Direito ambiental econômico. São Paulo: Saraiva, 2008.

ELALI, André. Tributação e regulação econômica: um exame da tributação como instrumento de regulação econômica na busca da redução das desigualdades regionais. São Paulo: MP, 2007.

FONTES, Karolina dos Anjos. O desafio constitucional da distribuição dos royalties depetróleo da bacia pré-sal para promoção de políticas públicas. Dissertação de Mestrado emDireito. Programa de Pós-graduação em Direito. UFRN. 2010. 128 f.

FURTADO, Celso. In: BIDERMAN, Ciro et al. Conversas com economistas brasileiros. São Paulo: Editora 34, 1997. Disponível em:

$<$ https://economiaeparaeconomista.files.wordpress.com/2011/10/conversa-comeconomistas.pdf $>$. Acesso em 02 de jun. 2015.

GRAU, Eros Roberto. A ordem econômica na Constituição de 1988. 11 ed. São Paulo: Malheiros, 2006.

MANOEL, Cacio Oliveira. A natureza jurídica dos royalties no ordenamento jurídicobrasileiro. 2003. 69 f. Monografia (Graduação) - Curso de Direito, Universidade Federal doRio Grande do Norte, Natal, 2003.

MELLO, Celso Antônio Bandeira de. Curso de direito administrativo. 26 ed. São Paulo: Malheiros, 2009.

MILARÉ, Edis. Direito ambiental brasileiro: a gestão ambiental em foco. 6 ed. São Paulo: Revista dos Tribunais, 2009.

NUSSBAUM, Martha. Creating Capabilities: The Human Development Approach. London: Belknap Press of Harvard University Press, 2011. 
PASSEGGUI, Alicia Violeta Botelho Sgadari.O princípio constitucional da redução dasdesigualdades regionais e os campos maduro-marginais de petróleo: aspectos regulatórios efiscais. Natal: EDUFRN, 2010.

PIKETTY, Thomas. O capital no século XXI. Tradução Monica Baumgarten de Bolle. Rio de Janeiro: Intrínseca, 2014.

SACHS, Ignacy. Caminhos para o desenvolvimento sustentável. Rio de Janeiro: Garamond, 2009.

SEN, Amartya. Development as freedom. New York: Alfred A. Knopf, Inc., 1999.

A ideia de justiça. Tradução Denise Bottmann e Ricardo Doninelli Mendes. São Paulo: Companhia das letras, 2011.

SERRA, Rodrigo. Concentração espacial das rendas petrolíferas e sobrefinanciamento das esferas de governo locais. In: PIQUET, Rosélia; SERRA, Rodrigo. Petróleo e região noBrasil: o desafio da abundância (org.). Rio de Janeiro: Garamond, 2007, p. 77-110.

Contribuição para o debate acerca da distribuição dos royalties petrolíferos noBrasil. Tese de doutorado. Campinas: Instituto de Economia, Doutorado em EconomiaAplicada, 2005.

SILVA, José Afonso da.Direito Ambiental Constitucional. 4 ed. São Paulo: Malheiros, 2002.

SIQUEIRA, Mariana de. Os desafios regulatórios do pré-sal e os seus reflexos na atuação da ANP. Direito e Liberdade: ESMARN, Natal, v. 13, n. 1, p.141-156, jan./jun., 2011.

Disponível em: <http://www.esmarn.tjrn.jus.br/revistas/index.php/revista_direito_e_liberdade/article/view/4 10>. Acesso em: 05 jan. 2015.

TORRONTEGUY, Alessandra Fölzke. A Aplicação dos Royalties do Petróleo e aefetividade dos direitos fundamentais sociais. 2009. 157 f. Dissertação (Mestrado) - Cursode Programa de Pós- Graduação em Direitos e Garantias Fundamentais, Faculdade de Direito de Vitória, Vitória, 2009. 
